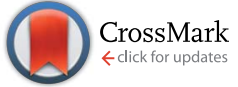

Cite this: Chem. Sci., 2015, 6, 6392

Received 25th May 2015

Accepted 27th July 2015

DOI: $10.1039 / \mathrm{c} 5 \mathrm{sc} 01886 \mathrm{~b}$

www.rsc.org/chemicalscience

\title{
A T-shaped $\mathrm{Ni}\left[\kappa^{2}-\left(\mathrm{CF}_{2}\right)_{4}-\right] \mathrm{NHC}$ complex: unusual $\mathrm{C}_{\mathrm{sp}^{3}}-\mathrm{F}$ and $\mathrm{M}-\mathrm{C}^{\mathrm{F}}$ bond functionalization reactions $\uparrow$
}

\author{
Nicholas O. Andrella, Alexandre J. Sicard, Serge I. Gorelsky, Ilia Korobkov \\ and R. Tom Baker*
}

\begin{abstract}
A T-shaped octafluoronickelacyclopentane-NHC complex is prepared and characterized. While the solidstate structure includes a weak isopropyl- $\mathrm{CH}_{3}$ agostic interaction, the reactivity of this complex with Lewisand Brønsted acids is clearly enhanced by its low coordination number. Reaction with Me ${ }_{3} \mathrm{SiOTf}$, for example, yielded a rare metal-heptafluorocyclobutyl complex whereas carboxylic acids gave substitution at the $\alpha$-carbon and/or $\mathrm{Ni}-\mathrm{C}^{\mathrm{F}}$ bond protonolysis to afford thermally robust $4 \mathrm{H}$-octafluorobutyl $\mathrm{Ni}$ complexes.
\end{abstract}

\section{Introduction}

Fluorocarbons and their derivatives are valuable as refrigerants, agrochemicals, unique solvents/surfactants and fluoropharmaceuticals, with annual sales of the latter alone in the billions of dollars. ${ }^{1}$ As the demand for fluorinated chemicals has increased, so too have synthetic methods for introducing fluorine and fluorocarbon groups. ${ }^{2-4}$ Despite recent advances, transition metal-mediated/-catalyzed routes are rare in comparison to the well-developed organometallic chemistry of hydrocarbons. ${ }^{5}$ The challenge rests in the stability of metalperfluoroalkyl (M-R $\mathrm{R}^{\mathrm{F}}$ ) bonds, relative to metal-alkyl bonds. ${ }^{6} \mathrm{M}-$ $\mathrm{C}^{\mathrm{F}}$ bonds are typically inert to processes such as insertion/alkyl migration reactions, vital to metal-mediated catalytic cycles. ${ }^{7}$ Moreover, $\mathrm{C}-\mathrm{F}$ bonds are stronger than $\mathrm{C}-\mathrm{H}$ bonds, ${ }^{\mathbf{1 a}, \boldsymbol{b}}$ posing another obstacle to metal-based approaches.

We are investigating perfluoronickelacyclopentane complexes (PNCPs) as platforms for functionalized fluorocarbons with an initial focus on fundamental stoichiometric reactions. PNCPs have been synthesized previously by reaction of tetrafluoroethylene ( $\mathrm{TFE}, \mathrm{CF}_{2}=\mathrm{CF}_{2}$ ) with $\mathrm{Ni}^{0}$ complexes. The displacement of $\mathrm{P}$ ligands by bidentate ligands has also been reported (Scheme 1). ${ }^{\mathbf{}}$

To date, reports concerning the reactivity of PNCPs are sparse: Burch and co-workers found that Lewis acidic $\mathrm{BF}_{3}$ effects fluoride abstraction from $\mathrm{C} \alpha$ and phosphine migration to the activated carbon (Scheme $2 \mathrm{a}$ )..$^{9}$ Extending this reaction to the unsymmetrical $\mathrm{P}^{\wedge} \mathrm{S}$ chelate, we showed that treatment with

Department of Chemistry and Centre for Catalysis Research and Innovation(CCRI), University of Ottawa, 30 Marie Curie, Ottawa, ON K1N 6N5 Canada

$\dagger$ Electronic supplementary information (ESI) available: Experimental details, NMR spectra and X-ray crystallographic information. CCDC files 968465 (2), 968466 (3), 968467 (4a), 1028645 (5c) and $1412522\left(3 \cdot \mathrm{H}_{2} \mathrm{O}\right)$; For ESI and crystallographic data in CIF or other electronic format see DOI: 10.1039/c5sc01886b excess isonitrile effected cleavage of the $\mathrm{Ni}-\mathrm{C}^{\mathrm{F}}$ bond (Scheme 2b). ${ }^{10}$ With phosphite co-ligands, a remarkable hydrogenolysis reaction enables the selective catalytic hydrodimerization of TFE (Scheme 2c). ${ }^{\mathbf{1 1}}$ As far as we know, this reaction is the only example of a perfluoro-metallacyclopentane participating in a catalytic cycle. ${ }^{\mathbf{1 2}}$

Our approach to metallacycle functionalization hinges on the reactivity of metal-activated $\mathrm{C} \alpha-\mathrm{F}$ bonds ${ }^{\mathbf{1 3}}$ wherein we replace a $\mathrm{C}-\mathrm{F}$ bond by $\mathrm{C}-\mathrm{Nu}$ vs. the current paradigm $\mathrm{C}-\mathrm{L}(\mathrm{Nu}=$ nucleophile, $\mathrm{L}=$ ligand). Using $\mathrm{N}$-heterocyclic carbenes (NHCs), ${ }^{14}$ we aimed to access low-coordinate PNCPs wherein the strong $\mathrm{M}-\mathrm{C}_{\mathrm{NHC}}$ bond may also prevent ligand migration to $\mathrm{C} \alpha$. There is considerable precedent for such an approach to lowcoordinate metal complexes. ${ }^{15}$ Hillhouse and coworkers prepared a two-coordinate nickel-imido complex bearing the exceptionally bulky IPr* ligand (analog of IPr with 2,6-bis(diphenyl-methyl)phenyl groups instead of 2,6-diisopropylphenyl). ${ }^{16}$ Similarly, Miyazaki and coworkers synthesized a Tshaped three-coordinate nickel(I) chloride species $\left[\mathrm{Ni}(\mathrm{IPr})_{2} \mathrm{Cl}\right]$ by treatment of two-coordinate $\left[\mathrm{Ni}(\mathrm{IPr})_{2}\right]$ with aryl chlorides. ${ }^{17}$ Also, Hartwig et al. synthesized a low-valent, three-coordinate palladium(II) norbornyl species [Pd(SIPr)(NHAr)(Nor)], which underwent facile $\mathrm{C}-\mathrm{N}$ bond reductive elimination when heated. ${ }^{18}$

In this report we show that low-coordinate NHC Ni perfluorometallacycles undergo facile $\mathrm{C}_{\mathrm{sp}^{3}}-\mathrm{F}$ and $\mathrm{M}-\mathrm{C}^{\mathrm{F}}$ bond cleavage as well as $\mathrm{C} \alpha$-functionalization. ${ }^{9}$ We also demonstrate

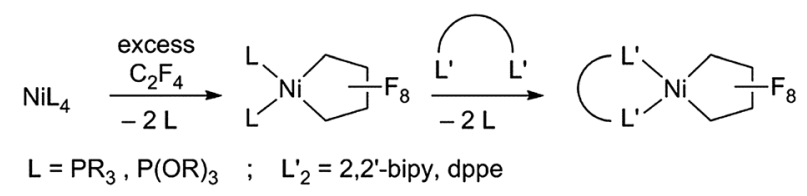

Scheme 1 Synthesis of perfluoronickelacyclopentanes. 
(a) Ca-F activation / phosphine migration (Burch et al.)

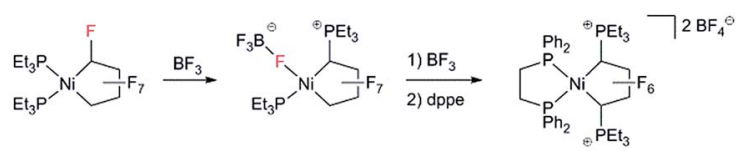

(b) Ca-F activation / phosphine migration and ring-opening (Baker et al.)

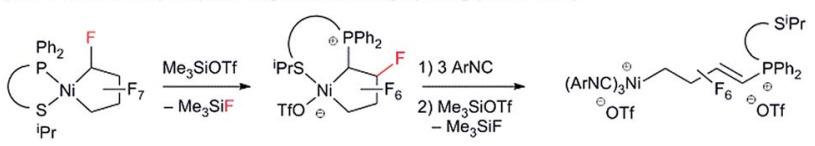

$\mathrm{L}=2,6$-xylylisocyanide

(c) Catalytic hydrodimerization of tetrafluoroethylene (Baker et al.)

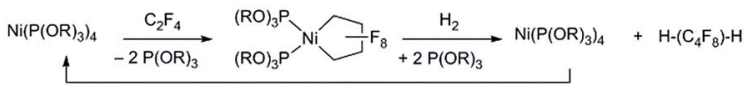

Scheme 2 Previously reported reactivity of perfluoronickelacyclopentanes.

the first migration of a fluoroalkyl to a reactive carbon center. This is significantly different from the reactivity previously observed for phosphine Ni perfluorometallacycle complexes. ${ }^{9}$

\section{Results and discussion}

Starting from bis(phosphite) $\operatorname{PNCPs}^{\mathbf{1 0}}$ (1a and $\mathbf{b}$ ) we were able to cleanly synthesize coordinatively-saturated or -unsaturated nickel perfluorometallacycles. Thus, 1a reacts smoothly with 1 equiv. of ItBu (ItBu $=1,3$-di-tert-butylimidazol-2-ylidene) to afford the NHC/phosphite product 2 (Scheme 3, top; X-ray structural characterization presented in $\mathrm{ESI} \dagger) .{ }^{19}$ Significantly, the reaction between the larger SIPr ligand [SIPr $=1,3$-bis(2,6diisopropylphenyl)imidazolin-2-ylidene] and a nickel metallacycle with sterically-demanding co-ligands (1b) results in displacement of both phosphite ligands, yielding the pseudothree-coordinate/14e-Ni(II) metallacycle 3 (Scheme 3, bottom).

The molecular structure of complex 3, as determined by single crystal X-ray diffraction, exhibits a T-shaped coordination about the $\mathrm{Ni}$ and features a weak agostic interaction with the isopropyl methyl group $\left(\mathrm{Ni}-\mathrm{C}=2.757(1) \AA\right.$; compare $\mathrm{Ni}-\mathrm{C}^{\mathrm{F}}$ bond distance trans to the NHC (1.934(1) $\AA$ ) with that trans to the agostic interaction (1.875(1) ̊) (Fig. 1a). The ${ }^{19}$ F NMR

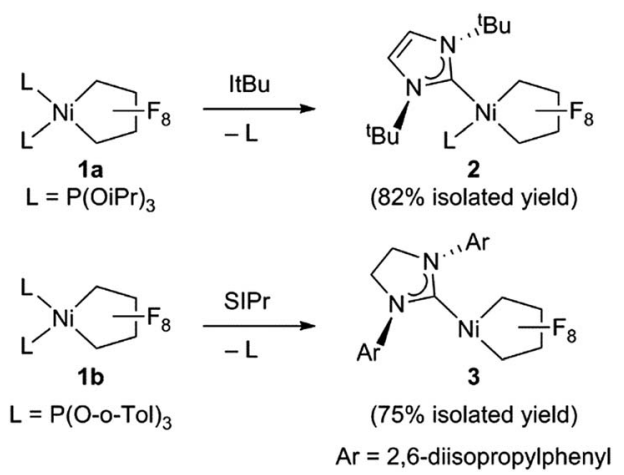

Scheme 3 Synthesis of NHC perfluoronickelacyclopentane complexes. spectrum of 3 in $\mathrm{C}_{6} \mathrm{D}_{6}$ is consistent with ideal $C_{2 \mathrm{v}}$ symmetry at room temperature, with only two distinct singlet resonances at $-101.9(\mathrm{~F} \alpha)$ and $-138.6 \mathrm{ppm}(\mathrm{F} \beta)$. While these resonances both broaden significantly at $213 \mathrm{~K}$, it is apparent that the T-flip interconversion encounters only a small energy barrier. ${ }^{20}$ To confirm this, we carried out DFT calculations (at the B3LYP/ TZVP level with and without the empirical dispersion correction of Grimme). ${ }^{21}$ Intriguingly, the calculations reveal two spinsinglet structures with a very small energy difference $\left(\Delta G_{298 \mathrm{~K}}=\right.$ 0.0-1.5 kcal mol$\left.{ }^{-1}\right)$. The first computed structure coincides well with the observed solid-state structure of 3; the 3-center bond order index between the $\mathrm{Ni}$ and the corresponding $\mathrm{C}-\mathrm{H}$ bond of 0.05 is much less than $8 / 27(\sim 0.3)$, the maximum possible value for a 3-center 2-electron bond. As a result, the Mayer valence index for Ni in structure 3 is only 3.09. The second structure $\left(3^{\prime}\right)$ features a weak $\eta^{3}$ interaction between the aryl group of the NHC ligand at the 4 th coordination site of the Ni atom (Fig. 1b). Mayer bond orders for the corresponding three Ni-C interactions are in the 0.02-0.05 range, with a total bond order of 0.09. This suggests a semi-bidentate binding mode for the class of NHC ligands possessing pendant aryl groups. From calculations with the dispersion correction, structure $3^{\prime}$ has the same Gibbs free energy as $\mathbf{3}$. Without the dispersion correction, structure $\mathbf{3}^{\prime}$ is actually $1.5 \mathrm{kcal} \mathrm{mol}^{-1}$ lower in energy than 3 . The 3 -coordinate structure with trigonal coordination around $\mathrm{Ni}$ and symmetric binding of the $\mathrm{C}_{4} \mathrm{~F}_{8}$ ligand is a transition state with a low energy $\left(\Delta G_{298 \mathrm{~K}}^{\ddagger}=2.1 \mathrm{kcal} \mathrm{mol}^{-1}\right.$ relative to 3$)$. Thus, it is clear that cleavage of the weak agostic and/or $\eta^{3}$-aryl bond is facile and allows for rapid reorientation of the ligands around the Ni center. Attempts to obtain evidence for structure $3^{\prime}$ by low temperature NMR were frustrated by dynamic processes associated with the T-flip and hindered rotations about the $\mathrm{M}-\mathrm{C}$ and perhaps $\mathrm{N}-\mathrm{C}$ bonds.

The HOMO of 3 ( $\varepsilon=-6.01 \mathrm{eV}$; Fig. 2, left) is localized on the $\mathrm{Ni}(87 \%)$, primarily from a $\mathrm{d}_{z^{2}}$ orbital contribution $(71 \%)$. Lower-lying orbitals display interactions between metal $\mathrm{d}_{x z}, \mathrm{~d}_{y z}$ orbitals and the $\pi$-system of the aryl group. ${ }^{22}$ The LUMO $(\varepsilon=$ $-1.96 \mathrm{eV}$; Fig. 3, right) is an anti-bonding combination of the metal $\mathrm{d}_{x^{2}-y^{2}}$ orbital (total Ni character of $45 \%$ ) with the $\pi$-donor

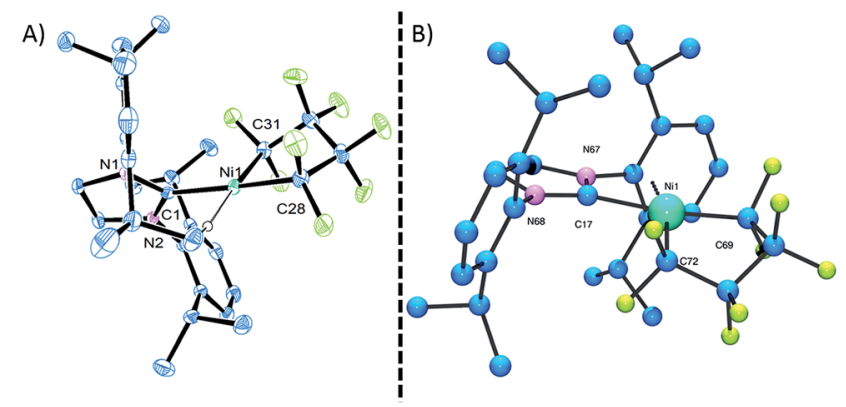

Fig. 1 (A) ORTEP representation of the molecular structure of 3 . Thermal-ellipsoid probabilities are set to $35 \%$ with hydrogen atoms omitted for clarity. The Ni-C(1) distance is 1.854(2) $\AA$. (B) Optimized structure of low energy $\mathrm{Ni}$-aryl isomer $3^{\prime} ; \mathrm{Ni}-\mathrm{C}_{\text {aryl }}$ distances are $=$ $2.818,3.329,3.379,4.166,4.204,4.543 \AA$. The Ni-C(17) distance is $1.989 \AA$. 

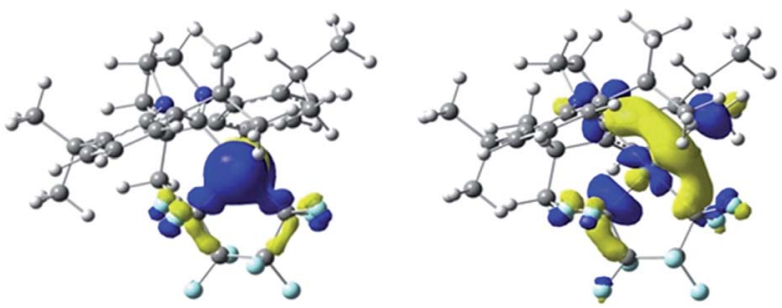

Fig. 2 The HOMO (left) and LUMO (right) of 3. Isosurface values of 0.04 au are used.

orbitals of the NHC and $\mathrm{C}_{4} \mathrm{~F}_{8}$ ligands. Thus, reactivity of the $\mathrm{M}-\mathrm{C}$ bond is likely under orbital control and arises from an interaction with the HOMO of 3 . In contrast, $\mathrm{C}-\mathrm{F}$ bond activation is likely a combination of orbital and charge control with a slant towards the latter as the hardness of the Lewis acid increases. $^{23}$

Initial studies on the $\mathrm{C}-\mathrm{F}$ bond activation reactions of 3 are promising in the context of synthesizing functionalized fluorocarbons by metal-mediated approaches. Firstly, when 3 is treated with the Lewis acid TMSOTf (TMS $=\mathrm{Me}_{3} \mathrm{Si}$, OTf $=$ $\mathrm{SO}_{3} \mathrm{CF}_{3}$ ), $\alpha$-fluoride-abstraction, accompanied by $\mathrm{Ni}-\mathrm{C}^{\mathrm{F}}$ bond cleavage and $\mathrm{C}^{\mathrm{F}}-\mathrm{C}^{\mathrm{F}}$ bond formation, furnishes a rare perfluorocyclobutyl complex $\mathbf{4 a}$ (Scheme 4, 75\% isolated yield). ${ }^{24}$ The driving force behind this transformation is likely related to the triflate leaving group ability and the formation of a strong $\mathrm{C}-\mathrm{C}$ bond..$^{25}$ Importantly, the NHC remains bound to the nickel atom (i.e., does not migrate to $\mathrm{C} \alpha$ ), potentially opening new pathways to functionalized fluorocarbon derivatives. Upon heating complex $4 \mathrm{a}\left(80^{\circ} \mathrm{C}\right.$ in $\left.\mathrm{C}_{6} \mathrm{D}_{6}, 24 \mathrm{~h}\right)$, perfluorocyclobutene is produced, presumably via a $\beta$-fluoride elimination mechanism, although the metal-containing co-product(s) have not yet been identified. ${ }^{26}$ Interestingly, a single OTf containing product can be discerned by ${ }^{19} \mathrm{~F}$ NMR $(-93.37 \mathrm{ppm})$ but a Ni-F signal could not be located. The ${ }^{1} \mathrm{H}$ NMR shows that the NHC remains intact. Upon addition of $\mathrm{PPh}_{3}$ to the reaction mixture, $\mathrm{PPh}_{3} \mathrm{~F}_{2}$

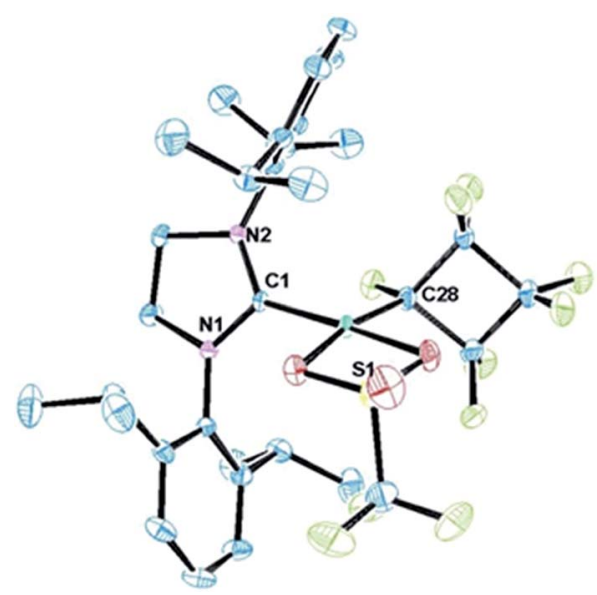

Fig. 3 ORTEP representation of the molecular structure of $4 a$ with thermal ellipsoid probabilities set to $30 \%$ and hydrogen atoms omitted for clarity. The $\mathrm{Ni}-\mathrm{C}(1)$ distance is $1.854(2) \AA$. was identified as a major product, suggesting formation of a $\mathrm{Ni}-$ F thermolysis co-product.

The distorted square planar structure of complex 4a (Fig. 3) features a bidentate triflate ligand which can also likely access the $\kappa^{1}$-mode in solution as evidenced by the simple ${ }^{19} \mathrm{~F}$ NMR spectrum $^{27}$ and observed tendency to eliminate. The perfluorocyclobutyl ring is nearly planar, the Ni-C bond is short $[1.890(2) \AA]$ due to the weak $\sigma$-trans influence ligand, and the $\mathrm{C} \alpha-\mathrm{F}$ bond distance $(1.384(3) \AA$ ) is considerably longer than the other $\mathrm{C}-\mathrm{F}$ bonds (average of $1.33 \AA$ ).

The reactivity enhancement offered by low-coordinate 3 is evidenced by the sluggish reaction of 4-coordinate complex 2 with TMSOTf to give a mixture of unidentified products. Indeed, monitoring the reaction of 3 and TMSOTf at $-25^{\circ} \mathrm{C}$ allowed for the identification of a $\mathrm{Ni}-\mathrm{C}_{4} \mathrm{~F}_{7}$ intermediate $5 \mathbf{a}$ apparently containing a $\mathrm{C} \alpha$-OTf linkage (triflate $\mathrm{CF}_{3}{ }^{19} \mathrm{~F}$ NMR resonance is coupled to $\mathrm{C} \alpha-\mathrm{F}:{ }^{5} J_{\mathrm{FF}}=11 \mathrm{~Hz}$ ). This is in contrast to previous suggestions of a metal fluorocarbene intermediate (Scheme 5). ${ }^{9}$

Having established that the NHC ligand remains bound to the metal upon fluoride-abstraction from 3, we shifted our focus to $\mathrm{C}-\mathrm{F}$ bond functionalization using Brønsted acids. Treatment of 3 with trifluoroacetic acid [TFA; $\mathrm{p} K_{\mathrm{a}}=3.4$ (DMSO)] ${ }^{28 a}$ gives HF and the more stable ( $v s$. 5a) trifluoroacetate-substituted metallacycle $\mathbf{5 b}$ that could be characterized spectroscopically at room temperature (Scheme 6). Nonetheless, accompanying formation of perfluoro-cyclobutene, presumably formed via an analogous structure to $\mathbf{4 a}$, led us to move to weaker Brønsted acids. Remarkably, reaction of 3 with acetic acid $\left[\mathrm{p} K_{\mathrm{a}}=12(\mathrm{DMSO})\right]^{28 b}$ (Scheme 6, bottom) yielded the stable ester metallacycle 5c $(30 \%$ isolated yield) as well as the $\mathrm{Ni}-\mathrm{C}^{\mathrm{F}}$ bond cleavage product $6 \mathbf{6}$ in a $1: 1$ ratio. At a similar acidity $\left[\mathrm{p} K_{\mathrm{a}}=11 \text { (DMSO) }\right]^{28 c}$ but increased steric bulk, 2,4,6-trimethyl-benzoic acid gave a $10: 1$ mixture favouring the ring cleavage product, $\mathbf{6 b}$.

The molecular structure of $\mathbf{5 c}$ features similar $\mathrm{Ni}-\mathrm{C}$ bond distances (1.895(7) vs. 1.896(6) §) and a distorted square planar coordination (Fig. 4). The functionalized heptafluoro-metallacyclopentane ring is puckered with the smallest $\mathrm{C}-\mathrm{C}$ bond distance being $\mathrm{C}(32) \alpha-\mathrm{C}(39) \beta[1.49(1) \AA]$. The carbonyl oxygen completes the nickel coordination sphere $(\mathrm{Ni}-\mathrm{O} 1=1.969(4) \AA)$.

The ${ }^{19}$ F NMR spectra of 5a-d are very similar and support our original proposal for the low temperature intermediate 5a in the

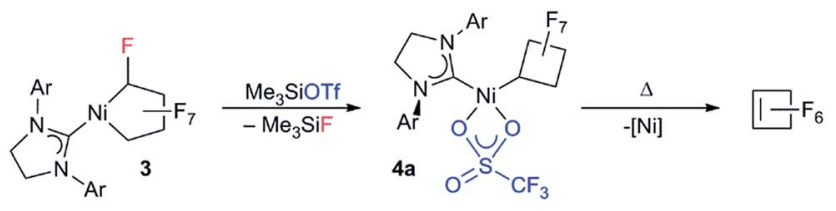

Scheme 4 Synthesis and decomposition of $4 a$.

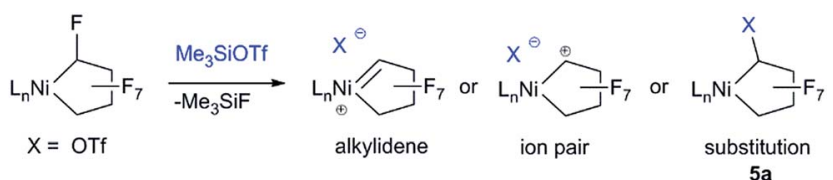

Scheme 5 Possible intermediates in the reaction of 3 with TMSOTf. 


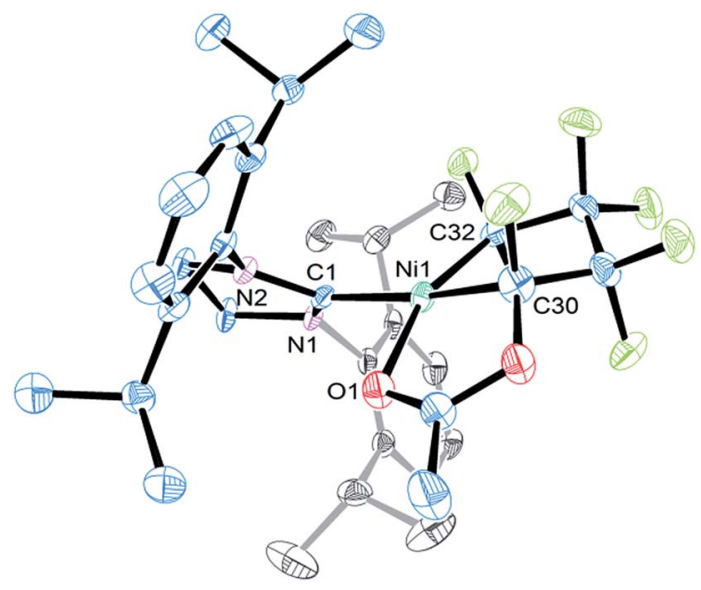

Fig. 4 ORTEP representation of the molecular structure of $5 \mathrm{c}$ with thermal ellipsoid probabilities set to $30 \%$ and hydrogen atoms omitted for clarity. The Ni-C(1) distance is $1.928(2) \AA$.

reaction of 3 with TMSOTf. The $\mathrm{C} \alpha-\mathrm{F}{ }^{19} \mathrm{~F}$ chemical shifts of the functionalized carbon, $(-117.2$ and $-119.2 \mathrm{ppm})$ can be compared with those of the phosphonium analogs $(-115.6$ and -117.8 ppm) shown in Scheme 2.

As expected, the ring-opened products $\mathbf{6 a}$ and $\mathbf{b}$ display nearly identical ${ }^{19} \mathrm{~F}$ NMR chemical shift patterns with the $\mathrm{C} \gamma-$ and $\mathrm{C} \delta$-F resonances distinguished by $\mathrm{F}-\mathrm{H}$ coupling of 6 and 52 $\mathrm{Hz}$, respectively. These unique complexes have been identified as their potassium cation adducts using ESI-MS (747.2 $\mathrm{g} \mathrm{mol}^{-1}$ and $851.4 \mathrm{~g} \mathrm{~mol}^{-1}$ respectively) and are surprisingly inert to thermolysis at $80{ }^{\circ} \mathrm{C}$ in $\mathrm{C}_{6} \mathrm{D}_{6}$ for $20 \mathrm{~h}$.

Considering the importance of esters as synthons in organic transformations ${ }^{29}$ this $\mathrm{C}-\mathrm{O}$ bond-forming reaction $\mathbf{3} \rightarrow \mathbf{5}$ is very appealing from the standpoint of synthesizing functionalized fluorocarbons. As such, understanding competing pathways for $\mathrm{M}-\mathrm{C}$ vs. $\mathrm{C}-\mathrm{F}$ bond cleavage would be valuable. ${ }^{30}$ Viable reaction pathways can be considered as proceeding via either 5- or 6membered transition states (Scheme 7). The selective $\mathrm{HF}$ elimination observed for TFA, is eroded as Ni-C bond protonolysis (orbital control) competes using acids of intermediate acidity (e.g. $\left.\mathrm{p} K_{\mathrm{a}} \sim 11\right) .{ }^{31}$ With the bulkier trimethylbenzoic acid, kinetic acidity factors in the tighter 5 -membered ring transition state could severely limit HF elimination. ${ }^{32}$

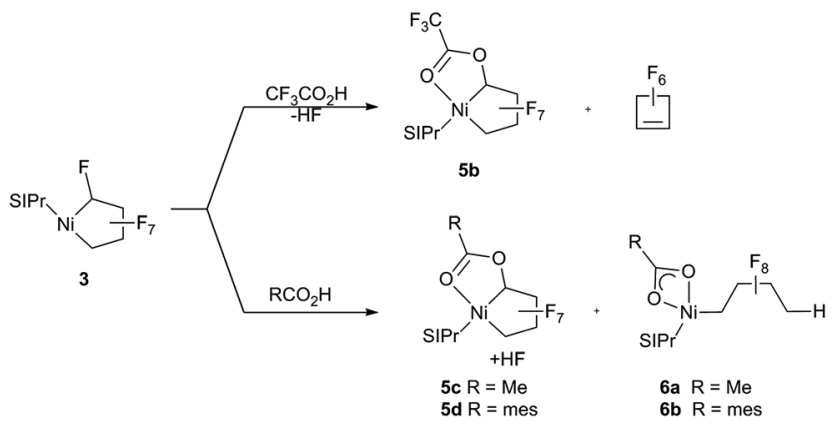

Scheme 6 Reaction of 3 with trifluoroacetic, acetic and 2,4,6-trimethylbenzoic acids.
1) C-F bond protonolysis

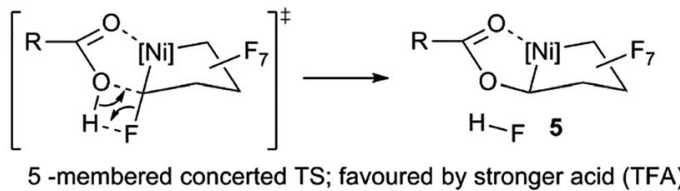

2) Metal-alkyl protonolysis

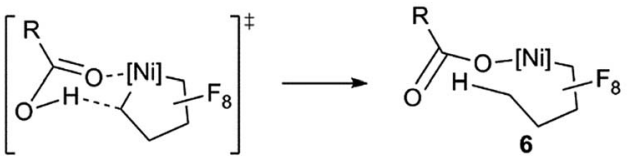

6 -membered concerted TS $\left(S_{E} 2\right)$; favoured with bulky weaker acid

Scheme 7 Proposed reaction pathways for $\mathrm{C}-\mathrm{F}$ activation vs. $\mathrm{Ni}-\mathrm{R}^{\mathrm{F}}$ protonolysis.

\section{Conclusions}

In summary, we have prepared the first NHC-perfluorometallacyclopentane complexes and exploited the bulky SIPr ligand to stabilize a pseudo-three-coordinate nickelacycle, 3. Importantly, 3 undergoes $\mathrm{C} \alpha-\mathrm{F}$ abstraction reactions without migration of the NHC ligand. Instead, we see an unprecedented migration of the fluoroalkyl to the reactive carbon center, giving rise to the novel perfluorocyclobutyl complex via $\mathrm{Ni}-\mathrm{C}^{\mathrm{F}}$ bond cleavage. More importantly, the low-coordinate nature of 3 allows for ring functionalization. Strong acids favour selective $\mathrm{C} \alpha$ functionalization, but the resulting products are unstable with respect to competing metallacycle ring contraction and elimination of perfluorocyclobutene. With less acidic reagents stable ring-functionalized products are formed but a competing $\mathrm{Ni}-\mathrm{C}^{\mathrm{F}}$ bond cleavage pathway comes into play and dominates for bulkier carboxylic acids. These are the first examples of selective functionalization of a PNCP and synthesis of thermally stable $\mathrm{Ni}-\mathrm{C}_{4} \mathrm{~F}_{8} \mathrm{H}$ complexes. These results are encouraging in the context of developing metallacycle-based routes to functionalized fluorocarbons.

Ongoing work is focused on (a) expanding the scope of ring functionalization substrates suitable for reactions with 3 and (b) reductive (see Scheme 2, above) and oxidative approaches for removing the functionalized fluorocarbon fragments from the metal. Preliminary results of the hydrogenolysis of compound 3 indicate enhanced reactivity towards $\mathrm{H}_{2}$ (i.e., at $7 \mathrm{psig}$ and $25^{\circ} \mathrm{C}$ ) vs. reported 4-coordinate phosphite variants. ${ }^{11 a}$ However, loss of selectivity ${ }^{33}$ is observed with the synthesis of two distinct products. Full details of these results will be published in due time.

\section{Acknowledgements}

We thank the NSERC and the Canada Research Chairs program for generous financial support and the University of Ottawa, Foundation for Innovation and Ontario Ministry of Economic Development and Innovation for essential infrastructure. N. O. A. gratefully acknowledges support from the province of Ontario, NSERC and the University of Ottawa (OGS and CGS-M/D). 


\section{Notes and references}

1 (a) R. D. Chambers, Fluorine in Organic Chemistry, Blackwell, Oxford, 2004; (b) P. Kirsch, Modern Fluoroorganic Chemistry: Synthesis, Reactivity, Applications, Wiley-VCH, Weinheim, 2 edn, 2013; (c) S. Purser, P. R. Moore, S. Swallow and V. Gouverneur, Chem. Soc. Rev., 2008, 37, 320; (d) I. Ojima, Fluorine in Medicinal Chemistry and Chemical Biology, John Wiley \& Sons, Ltd, Chichester, 2009.

2 Stoichiometric $[\mathrm{Cu}]-\mathrm{CF}_{3}$ reagents for trifluoromethylation of organic substrates, particularly aryl halides: (a) H. Morimoto, T. Tsubogo, N. D. Litvinas and J. F. Hartwig, Angew. Chem., Int. Ed., 2011, 50, 3793; (b) G. G. Dubinina, H. Furutachi and D. A. Vicic, J. Am. Chem. Soc., 2008, 130, 8600; (c) D. M. Wiemers and D. J. Burton, J. Am. Chem. Soc., 1986, 108, 832.

3 Metal-catalyzed $\mathrm{C}-\mathrm{F}$ and $\mathrm{C}-\mathrm{CF}_{3}$ bond formation: (a) T. Furuya, A. S. Kamlet and T. Ritter, Nature, 2011, 473, 470; (b) E. J. Cho, T. D. Senecal, T. Kinzel, Y. Zhang, D. A. Watson and S. L. Buchwald, Science, 2010, 328, 1678; (c) V. V. Grushin, Acc. Chem. Res., 2010, 43, 160; (d) J. M. Brown and V. Gouverneur, Angew. Chem., Int. Ed., 2009, 48, 8610; (e) K. L. Hull, W. Q. Anani and M. S. Sanford, J. Am. Chem. Soc., 2006, 128, 7134.

4 Non-metal based approaches to introducing fluorocarbon fragments to organic substrates: (a) F. Wang, T. Luo, J.-B. Hu, Y. Wang, H. S. Krishnan, P. V. Jog, S. K. Ganesh, G. K. S. Prakash and G. A. Olah, Angew. Chem., Int. Ed., 2011, 50, 7153 ( $\mathrm{CF}_{2}$ addition to alkenes); (b) R. P. Singh, G. Cao, R. L. Kirchmeier and J. M. Shreeve, J. Org. Chem., 1999, 64, 2873. ( $\mathrm{Me}_{3} \mathrm{Si}-\mathrm{CF}_{3}$ addition to carbonyl groups).

5 (a) H.-J. Arpe, Industrial Organic Chemistry, Wiley-VCH, Weinheim, 5th edn, 2010; (b) Applied Homogeneous Catalysis with Organometallic Compounds, ed. B. Cornils and W. A. Herrmann, Wiley-VCH, New York, 1996.

6 (a) F. L. Taw, A. E. Clark, A. H. Mueller, M. T. Janicke, T. Cantat, B. L. Scott, P. J. Hay, R. P. Hughes and J. L. Kiplinger, Organometallics, 2012, 31, 1484; (b) R. P. Hughes, Adv. Organomet. Chem., 1990, 31, 183; (c) J. A. Morrison, Advances in Organometallic Chemistry: Trifluoromethyl-Containing Transition Metal Complexes, Academic Press, 1993, vol. 35; (d) P. J. Brothers and W. R. Roper, Chem. Rev., 1988, 88, 1293.

7 [Mn] $-\mathrm{CF}_{3}$ inert to $\mathrm{CO}$ migratory-insertion: S. K. Shin and J. L. Beauchamps, J. Am. Chem. Soc., 1990, 112, 2057.

8 (a) M. Ohashi, M. Shibata, H. Saijo, T. Kambara and S. Ogoshi, Organometallics, 2013, 32, 3631; (b) W. GasafiMartin, G. Oberendfellner and K. von Werner, Can. J. Chem., 1996, 74, 1922; (c) M. Green, A. Laguna, J. L. Spencer and F. G. A. Stone, J. Chem. Soc., Dalton Trans., 1977, 1010; (d) J. Browning, H. D. Empsall, M. Green and F. G. A. Stone, J. Chem. Soc., Dalton Trans., 1973, 381; (e) C. S. Cundy, M. Green and F. G. A. Stone, J. Chem. Soc. A, 1970, 1647; $(f)$ M. Green, R. B. L. Osborn, A. J. Rest and F. G. A Stone, J. Chem. Soc. A, 1968, 2525; $(g)$
P. M. Treichel and F. G. A. Stone, Adv. Organomet. Chem., 1964, 1, 143.

9 R. R. Burch, J. C. Calabrese and S. D. Ittel, Organometallics, 1988, 7, 1642.

10 K. A. Giffin, D. J. Harrison, I. Korobkov and R. T. Baker, Organometallics, 2013, 32, 7424.

11 (a) R. T. Baker, R. P. Beatty, W. B. Farnham and R. L. Wallace Jr, US Pat., 5670679, 1997; (b) Generation of perfluorocyclobutene or perfluorocyclobutane from an iron perfluorometallacyclopentane complex, under thermal or thermal/oxidizing $\left(\mathrm{Br}_{2}\right) \quad$ conditions, respectively, T. A. Manuel, S. L. Stafford and F. G. A. Stone, J. Am. Chem. Soc., 1961, 83, 249.

12 M. Ohashi and S. Ogoshi, Catalytic Transformations of Fluorinated Olefins. in Topics in Organometallic Chemistry, Springer, Switzerland, 2014.

13 Activation of $\mathrm{C}-\mathrm{F}$ bonds in $[\mathrm{M}]-\mathrm{R}^{\mathrm{F}}$ complexes: (a) R. P. Hughes, J. Fluorine Chem., 2010, 131, 1059; (b) J. Goodman, V. V. Grushin, R. B. Larichev, S. A. Macgregor, W. J. Marshall and D. C. Roe, J. Am. Chem. Soc., 2009, 131, 4236; (c) S. A. Garratt, R. P. Hughes, I. Kovacik, A. J. Ward, S. Willemsen and D. Zhang, J. Am. Chem. Soc., 2005, 127, 15585; (d) H. Torrens, Coord. Chem. Rev., 2005, 249, 1957; (e) D. Huang, P. R. Koren, K. Folting, E. R. Davidson and K. G. Caulton, J. Am. Chem. Soc., 2000, 122, 8916; (f) T. G. Richmond and D. F. Shriver, Organometallics, 1984, 3, 314; $(g)$ T. G. Richmond and D. F. Shriver, Organometallics, 1983, 2, 1061, see also ref. $8 a$.

14 (a) R. H. Crabtree, J. Organomet. Chem., 2005, 690, 5451; (b) D. J. D. Wilson, S. A. Couchman and J. L. Dutton, Inorg. Chem., 2012, 51, 7657.

15 D. J. Nelson and S. P. Nolan, Chem. Soc. Rev., 2013, 42, 6723. 16 C. A. Laskowsky, A. J. Miller, G. L. Hillhouse and T. R. Cundari, J. Am. Chem. Soc., 2011, 133, 771.

17 S. Miyazaki, Y. Koga, T. Matsumoto and K. Matsubara, Chem. Commun., 2010, 46, 1932.

18 P. S. Hanley, S. L. Marquard, T. R. Cundari and J. F. Hartwig, J. Am. Chem. Soc., 2012, 134, 15281.

$19 \mathrm{Ni}-\mathrm{RF}$ bond lengths for structure 2 (see ESI $\dagger$ ): 1.956(1) (trans to $\mathrm{P}$ ); $1.945(1) \AA$ (trans to $\mathrm{C}$ ). $\mathrm{Ni}-\mathrm{C}(\mathrm{NHC})$ bond length for 2: 1.945(1) ̊.

20 See ESI page S14 for low temperature NMR spectra. $\dagger$ 21 S. Grimme, J. Comput. Chem., 2006, 27, 1787.

22 See ESI page S29. $\dagger$

23 N. Islam and D. C. Gosh, Theoretical and Computational Research in the $21^{\text {st }}$ century, ed. N. Islam, CRC Press, Boca Raton, 2014, ch. 1, pp. 1-58.

24 To the best of our knowledge, the only previously reported metal perfluorocyclobutyl complexes are: $(a)$ B. L. Dyatkin, B. I. Martynov, L. G. Martynova, N. G. Kizim, S. R. Sterlin, Z. A. Stumbrevichute and L. A. Federov, J. Organomet. Chem., 1973, 57, 423; (b) B. L. Dyatkin, S. R. Sterlin, B. I. Martynov, E. I. Mysov and I. L. Knunyants, Tetrahedron, 1971, 27, 2843.

25 (a) The leaving group ability of OTf, R. K. Crossland, W. E. Wells and V. J. Shiner, J. Am. Chem. Soc., 1971, 93, 4217. 
26 (a) T. Miura, Y. Ito and M. Murakami, Chem. Lett., 2008, 37, 1006; (b) C. J. Bourgeois, R. P. Hughes, J. Yuan, A. G. DiPasquale and A. L. Rheingold, Organometallics, 2006, 25, 2908.

27 For NMR spectra of compound 4a see pages S21-S22. $\dagger$

28 (a) M. H. Haindl, M. B. Schmid, K. Zeitler and R. M. Gschwind, RSC Adv., 2012, 2, 5941; (b) T. Cohen, D. A. Bennett and A. J. Mura Jr, J. Org. Chem., 1976, 41, 2507; (c) J. Jover, R. Bosque and J. Sales, QSAR Comb. Sci., 2008, 27, 563.

29 W. Riemenschneider and H. M. Bolt, Esters, Organic, in Ullman's Encyclopedia of Industrial Chemistry, Wiley-VCH, Weinheim, 2005.
30 Previous work showed protonation of $\mathrm{C}-\mathrm{F}$ bond instead of Ir- $\mathrm{CH}_{3}$ using a strong acid: R. P. Hughes, D. Zhang, L. N. Zakharov and A. L. Rheingold, Organometallics, 2002, 21, 4902.

31 E. W. Kalberer, J. F. Houlis and D. M. Roddick, Organometallics, 2004, 23, 4112-4115.

32 Similar reactivity was previously observed for 3-membered perfluorinated metallacycles: W. Xu, H. Sun, Z. Xiong and X. Li, Organometallics, 2013, 32, 7122.

33 R. P. Hughes and J. M. Smith, J. Am. Chem. Soc., 1999, 121, 6084. 